\title{
A aprendizagem dos clíticos de terceira pessoa do espanhol por universitários brasileiros: o efeito e a durabilidade da intervenção instrucional ${ }^{1}$
}

\section{The Learning of Third-Person Clitics of Spanish by Brazilian University Students: the Effect and Durability of Instructional Intervention}

Eduardo de Oliveira Dutra*

*Universidade Federal do Pampa (Unipampa), Bagé, Rio Grande do Sul / Brasil edualeunipampa@gmail.com https://orcid.org/0000-0003-1612-1395

\begin{abstract}
RESUMO: Neste estudo, analisamos e discutimos o efeito e a durabilidade da intervenção instrucional na aprendizagem dos clíticos de terceira pessoa do espanhol por universitários brasileiros. Para fins de tratamento estatístico, os dados foram submetidos ao software International Business Machine Statistical Package for Social Studies (SPSS), a partir do qual fizemos uso de frequência relativa, teste de $\chi^{2}$ e teste de Anova de medidas repetidas. Fizeram parte deste estudo dez participantes, alunas de um curso de Letras Português/Espanhol e Respectivas Literaturas de uma universidade pública. Os resultados, de modo geral, sugeriram que a intervenção pedagógica produziu avanço e efeitos duráveis, respectivamente, das formas simples e complexas que seguem em processo de aquisição entre as alunas participantes.
\end{abstract}

PALAVRAS-CHAVE: clíticos de terceira pessoa; instrução com foco na forma; espanhol.

\footnotetext{
${ }^{1}$ Este trabalho é um recorte de uma pesquisa de doutorado que foi realizada, sob orientação da Profa. Dra. Marília dos Santos Lima, na Universidade do Vale do Rio do Sinos (Unisinos). O período de doutorado sanduíche, na Universidade de Salamanca, Espanha, foi financiado pelo Programa de Doutorado Sanduíche no Exterior da Coordenação de Aperfeiçoamento Pessoal de Nível Superior (Capes).
} 


\begin{abstract}
In this study, we analyze and discuss the effect and the durability of the instructional intervention in the learning of third person clitics of Spanish by Brazilian university students. For statistical purposes, the data were submitted to the International Business Machine Statistical Package for Social Studies (SPSS) software, from which we have used relative frequency, $\chi^{2}$ test and repeated measures of Anova test. This study included 10 participants, students of a Portuguese and Spanish Language Teacher Education Program from a public university. The results, in general, suggested that the pedagogical intervention has produced progress and durable effects, respectively, of the simple and complex forms which are still being acquired by these studentparticipants.
\end{abstract}

KEYWORDS: third person clitics; focus on form instruction; Spanish.

\title{
1 Introdução
}

Os clíticos acusativos e dativos de terceira pessoa têm sido objeto de estudo de investigações descritivas ou relacionais (GONZÁLEZ, 1994; LOZADA, 2007; SIMÕES, 2010; VILLALBA, 1995; YOKOTA, 2007), na área de aprendizagem do espanhol como segunda língua ${ }^{2}$ (doravante L2), no país. Existe uma tendência de os brasileiros, inclusive em níveis avançados, apresentarem, em suas produções, formas alternativas que coexistem com as formas clíticas, ainda que em menor grau, se comparados aos níveis iniciais de estudo, o que caracteriza como instável a sua língua no que tange ao sistema pronominal do espanhol (CRUZ, 2001). Como estratégias de retomada dos sintagmas complementos, há a presença de pronomes tônicos, formas nulas e sintagmas nominais repetidos, entre outras formas alternativas, na língua dos aprendizes, o que sugere, segundo os estudos supramencionados, a influência da língua materna, português brasileiro (doravante PB), no processo de aprendizagem do espanhol.

$\mathrm{Na}$ área de aquisição de segunda língua (doravante ASL), vários estudos (CARVALHO, 2017; DUTRA, 2019; FREITAS, 2014; GONTIJO, 2001; LIMA JÚNIOR, 2008; LOOSE, 2006; NASCIMENTO, 2009; NORRIS; ORTEGA, 2000; MORAES, 2014; MORAES; DUTRA; SIMIONI, 2018; PEROZZO, 2013; PREUSS, 2005; SPADA, 1997; SPADA; TOMITA, 2010; TODE, 2007), a respeito da Instrução com Foco na Forma (doravante IFF), têm apontado benefícios do direcionamento da atenção dos aprendizes para

\footnotetext{
${ }^{2}$ Neste estudo, não distinguimos segunda língua de língua estrangeira. Tampouco diferenciamos aquisição de aprendizagem.
} 
formas específicas do insumo recebido no processo de aquisição da L2. No contexto brasileiro, na ASL, a interação entre o grau de complexidade das formas linguísticas e o tratamento instrucional é uma temática pouco explorada. Além disso, a pesquisa desenvolvida (FREITAS, 2014), nesse sentido, apesar de sugerir benefícios instrucionais, não contempla as formas clíticas de terceira pessoa do espanhol como objeto de instrução

Neste estudo, de caráter quase-experimental, em curto e em médio prazos, investigamos em que medida a intervenção instrucional interage com o grau de complexidade ${ }^{3}$ das formas sob análise (SPADA; TOMITA, 2010). Dito de outra maneira, examinamos, ao longo das etapas de coleta de dados, o nível de interação entre o tratamento instrucional, os clíticos acusativos de terceira pessoa (forma simples), como em $\boldsymbol{L} \boldsymbol{a}$ compro, e essas formas clíticas em situação de coocorrência com os clíticos dativos de terceira pessoa (formas complexas), no caso de $\boldsymbol{S} \boldsymbol{e} \boldsymbol{l o}$ vendo. Para fins de orientação, a seguir, apresentamos o modo como organizamos este artigo. Após a introdução, apresentamos a fundamentação teórica. Na sequência, indicamos a metodologia, a qual é seguida da análise e discussão dos resultados. Por último, trazemos as considerações finais.

\section{A realização dos objetos diretos e indiretos anafóricos no português brasileiro e no espanhol}

O PB e o espanhol apresentam estruturas assimétricas em distintos níveis linguísticos. A título de exemplo, podemos mencionar a realização dos objetos direto e indireto anafóricos em ambas as línguas. $\mathrm{O}$ espanhol opta preferencialmente pela retomada dos sintagmas complementos por formas clíticas, ao passo que o PB o faz por sintagmas nominais e preposicionais, pronomes tônicos e, com mais frequência, por formas nulas. A seguir, trazemos considerações (DUTRA; SIMIONI; LIMA, 2016) acerca das estratégias utilizadas na retomada dos sintagmas complementos em espanhol e no PB:

\footnotetext{
${ }^{3}$ A classificação do grau de complexidade das formas clíticas de terceira pessoa do espanhol ocorreu a partir de visão psicolinguística (para mais detalhes, ver DUTRA, 2019).
} 
- O PB apresenta como estratégias de realização do objeto direto anafórico as seguintes formas alternativas: clítico, forma nula, pronome tônico, repetição do sintagma nominal e the (com a realização [li]). Em comparação, em espanhol, o pronome tônico não parece ser uma possibilidade de realização do objeto direto anafórico;

- O PB pode realizar o objeto indireto anafórico dos seguintes modos: clítico, preposição seguida de pronome tônico ou de sintagma nominal pleno, pronome fraco e forma nula, enquanto o pronome fraco e a forma nula não parecem ser opções de realização do objeto indireto anafórico em espanhol;

- O clítico, em PB, é a variante menos frequente no que tange à fala, ao passo que, em espanhol, o clítico é a variante predominante;

- A forma nula é a variante mais frequente na fala em PB. Em contraste, a forma nula não é tão frequente em espanhol, mas pode ocorrer como forma de realização do objeto direto anafórico nos casos em que o antecedente é [-específico] ou, nas variedades quitenha e paraguaia, quando o antecedente é [-animado]. Além disso, na variedade uruguaia, a forma nula pode expressar o objeto direto anafórico, desde que este esteja coocorrendo com um objeto indireto.

Em resumo, o uso da forma nula, no lugar do clítico acusativo de terceira pessoa, é mais frequente no PB do que no espanhol, que apresenta contexto linguístico restrito nesse sentido. Quanto às formas linguísticas de preenchimento e de retomada dos sintagmas complementos de terceira pessoa, referentes à função acusativa, em ambas as línguas, é possível afirmamos que elas se assemelham no primeiro caso. Contudo, apresentam um maior número de divergências no segundo caso, uma vez que o espanhol opta preferencialmente pelo emprego do clítico acusativo de terceira pessoa, ao passo que o $\mathrm{PB}$, na modalidade espontânea de língua falada, não se limita unicamente a formas pronominais no momento da retomada dos sintagmas complementos.De modo similar ao caso acusativo, há maior possibilidade de estratégias de retomada dos sintagmas complementos de terceira pessoa, no PB, em situação de coocorrência de objetos direto e indireto anafóricos, em comparação ao espanhol. 


\section{A instrução com foco na forma: uma contextualização}

Estudos referentes à IFF (CARVALHO, 2017; DUTRA, 2019; FREITAS, 2014; MORAES, 2014; MORAES; DUTRA; SIMIONI, 2018; NORRIS; ORTEGA, 2000; SPADA, 1997; SPADA; TOMITA, 2010; TODE, 2007) têm apontado, no processo de aprendizagem da L2, benefícios instrucionais, tais como: efeitos duráveis; aumento de velocidade na aprendizagem de traços linguísticos; redução de transferência da L1 para a L2; eficácia na aquisição de traços simples e complexos; aprendizagem de formas simples e/ou complexas como conhecimento linguístico, entre outros benefícios.

Spada (1997, p. 73, tradução nossa) define a IFF como "qualquer esforço pedagógico que é usado para chamar implícita ou explicitamente a atenção do aprendiz para forma da língua. Isso pode incluir o ensino da língua por meio de regras gramaticais e/ou reações para erros do aprendiz (feedback corretivo)". ${ }^{4}$

A definição anterior de IFF, em comparação a outros conceitos (ELLIS, 2001; LONG; ROBINSON, 1998; WILLIAMS; EVANS, 1998), é mais abrangente, uma vez que contempla tipos de instrução (explícita e implícita) e estratégias pedagógicas (ensino de regras e feedback corretivo). A palavra forma não é sinônimo de gramática, visto que pode abranger aspectos da pragmática, gramática, léxico e fonologia referentes à linguagem (ELLIS, 2001).

Existem técnicas variadas ou tarefas que podem ocasionar a percepção de formas linguísticas específicas, por parte dos aprendizes, no insumo recebido. Spada (2010), a partir da análise de estudos relacionados à IFF, explicou que a instrução explícita remetia à situação na qual professores forneciam instruções e feedback corretivo, o que incluía o uso de metalinguagem e sinais claros para os alunos de que havia uma maneira certa e errada de dizer/escrever algo.

Em relação a esse último tipo de estratégia pedagógica, a correção explícita é um tipo de feedback no qual o professor fornece a forma correta e claramente indica que a produção do aluno estava incorreta. Em

\footnotetext{
${ }^{4}$ No original: “Any pedagogical effort that is used to implicitly or explicitly call the student's attention to the form of the language. This may include direct teaching of language through grammar rules and / or reactions to the learner's errors".
} 
comparação, o feedback metalinguístico é um movimento corretivo no qual o professor fornece informações ou perguntas relacionadas à formação correta do enunciado do aluno (LYSTER; RANTA, 1997).

Norris e Ortega (2000) enquadraram os estudos de sua metanálise como pertencentes à instrução explícita se a explicação da regra compreendia parte da instrução ou se os alunos fossem diretamente convidados a prestar atenção a traços específicos e tentassem chegar a generalizações metalinguísticas por conta própria. Logo, a instrução explícita pode abranger feedback corretivo, metalinguagem, obtenção, de modo indutivo, de regra(s) da língua-alvo e explicações a respeito de seu funcionamento.

A instrução também pode ser baseada na compreensão ou na produção. Em função do recorte, focamos essa última modalidade de instrução, baseada em habilidade, que pretende promover a produção adequada do objeto linguístico de instrução. Em virtude disso, o feedback corretivo é dirigido a qualquer erro que o aprendiz comete nas tarefas de produção (SHINTANI; LI; ELLIS, 2013).

A partir da Hipótese da Produção Compreensível, examinamos duas possíveis funções que a produção (oral e escrita) pode exercer no processo de aprendizagem de uma L2 (SWAIN, 1995; 1998; 2005). É possível que a produção linguística desencadeie a percepção do novo traço linguístico e da diferença existente entre a sua representação na língua de aprendiz e no insumo na língua-alvo (Hipótese da Percepção da Lacuna ${ }^{5}$ ).

Além disso, a produção dos estudantes, durante a aprendizagem de uma L2, também pode estar relacionada à formulação e à comprovação de hipóteses. Por conseguinte, provavelmente a produção linguística dos aprendizes seja um meio pelo qual eles testam hipóteses sobre como funcionam novas formas linguísticas na língua-alvo. Swain (2005) explica que o processo em que os aprendizes modificam sua produção, em reposta ao feedback, faz parte da aprendizagem. Contudo, segundo essa pesquisadora, não se tem demonstrado que a produção reprocessada prediz aprendizagem.

$\mathrm{Na}$ sala de aula de L2, a administração da intervenção instrucional pode ocorrer, durante a preparação para tarefas comunicativas ou, posteriormente, em tarefas nas quais os estudantes experenciaram dificuldade no que diz respeito à aplicação de um traço particular da línguaalvo (SPADA; LIGHTBOWN, 2008). Essa modalidade de instrução,

${ }^{5}$ Noticing the Gap Hypothesis. 
pautada no momento instrucional, é denominada Instrução com Foco na Forma Isolada (doravante IFFI).

Ainda que a IFFI seja adotada separadamente de tarefas comunicativas ou de instrução baseada no conteúdo, esse tipo de abordagem não equivale à instrução com foco nas formas (LONG, 1991), visto que esse tipo de ensino está centrado unicamente na estrutura da língua (SPADA; LIGHTBOWN, 2008). Além disso, apesar da IFFI integrar um tratamento em que o ensino é isolado da prática comunicativa, esse tipo de instrução pode acontecer em fase anterior ou posterior ao desenvolvimento de tarefas comunicativas (SPADA; LIGHTBOWN, 2008). Portanto, é possível o uso de estratégia pedagógica, baseada na instrução explícita, de natureza isolada, sem que se prescinda do equilíbrio entre forma e comunicação que rege a IFF. Com base em Spada e Lightbown (2008), apontamos, a seguir, três situações nas quais a aplicação da IFFI pode exercer papel relevante na aprendizagem da L2.

(i) A IFFI é útil quando a L1 tem forte influência sobre as formas da L2;

(ii) A IFFI pode ser benéfica com traços linguísticos que são relativamente simples, para fins de explicação ou ilustração, contudo essas formas não são salientes na oralidade;

(iii) A IFFI também pode auxiliar a garantir que os alunos tenham oportunidades de aprender formas poucos frequentes no idioma a que estão expostos na sala de aula que está centrada no ensino comunicativo da língua-alvo ou na instrução baseada no conteúdo.

No que tange à presente pesquisa, a opção pela IFFI encontra suporte na situação (i), visto que, segundo mencionamos anteriormente, existe influência do PB no processo de aprendizagem dos clíticos de terceira pessoa do espanhol. Além disso, cabe destacarmos que, se, em curto prazo, houve o aumento de frequência das formas clíticas de terceira pessoa, a intervenção instrucional produziu efeito. Já a durabilidade, em médio prazo, corresponde à manutenção praticamente do mesmo índice, que foi obtido em curto prazo, de frequência das formas sob análise. Por último, o avanço remete ao aumento contínuo de produtividade das formas clíticas de terceira pessoa ao longo das etapas posteriores à intervenção instrucional.

Para a avaliação do intake e da aprendizagem, com base em Freitas (2014), analisamos, respectivamente, os pós-testes imediatos e os pós- 
testes postergados. Por um lado, consideramos intake $e^{6}$ sempre que o índice do pós-teste imediato aponte aumento de frequência das formas-alvo em comparação aos valores do pré-teste. Por ouro lado, assumimos estruturasalvo adquiridas ${ }^{7}$ quando for usada e/ou identificada categoricamente a estrutura-alvo, de modo adequado, em contextos favoráveis à sua frequência. A partir do exposto, podemos observar que o intake está relacionado ao efeito, ao passo que a aprendizagem tem relação com a durabilidade/avanço.

\section{Metodologia}

Deste estudo, de natureza quase-experimental, fizeram parte dez estudantes do curso de Letras Espanhol/Português e Respectivas Literaturas de uma universidade pública, localizada no interior do Rio Grande do Sul. Essas estudantes integravam o terceiro, quinto e sétimo semestres. Para aplicação e coleta de dados, contamos com a participação colaborativa de dois professores do curso referido. Os objetivos, que nortearam o presente estudo, foram:

- Verificar os efeitos instrucionais sobre a frequência das formas simples e complexas do espanhol, através da análise da diferença percentual entre o pré-teste e o pós-teste imediato (curto prazo);

- Averiguar a durabilidade dos efeitos instrucionais em relação à produtividade das formas simples e complexas do espanhol, por meio do exame da diferença percentual entre o pós-teste imediato e o pósteste postergado (médio prazo).

As hipóteses, correspondentes aos objetivos supramencionados, são as que seguem:

- A IFF produzirá efeitos benéficos, em curto prazo, por meio do aumento dos índices alusivos à acuidade das formas simples e complexas do espanhol;

- Os efeitos instrucionais serão duradouros, isto é, haverá, em médio prazo, a estabilidade e/ou avanço dos índices referentes à acuidade das formas simples e complexas do espanhol.

\footnotetext{
${ }^{6}$ Procedimento distinto de Freitas (2014), visto que a autora analisa os índices do pós-teste imediato e considera intake se os índices de frequência forem superiores a $50 \%$.

${ }^{7}$ Procedimento idêntico ao de Freitas (2014).
} 
A seleção das participantes ocorreu tendo em vista os seguintes critérios: ser brasileiro (a); não ter ascendência hispânica; ter cursado, no mínimo, dois semestres de disciplinas de espanhol e participar de todas as etapas de coleta de dados. Para a obtenção de dados, esta pesquisa contou com três etapas, a saber: uma etapa anterior à intervenção instrucional (aplicação de pré-testes) e duas etapas posteriores ao tratamento instrucional (administração de pós-testes imediatos e postergados). No que concerne ao intervalo entre a intervenção instrucional e as fases pós-instrucionais, houve variação, na primeira fase, de três a quatro semanas (curto prazo), e, na segunda etapa, de nove e dez semanas (médio prazo).

A intervenção instrucional, destinada ao ensino das formas simples e complexas do espanhol, abrangeu as seguintes estratégias pedagógicas: informações contrastadas entre o PB e o espanhol, a respeito das formasalvo, feedback corretivo, instrução explícita, tarefa de compreensão e tarefas de produções livres e controladas. Entretanto, assinalamos que foi a instrução explícita a que predominou, uma vez que as demais estratégias pedagógicas incluíram a retomada de questões relacionadas às formas clíticas de terceira pessoa, via descrição de seu funcionamento na língua-alvo e metalinguagem.

Os instrumentos, para a obtenção dos dados, consistiram em prétestes, pós-testes imediatos e pós-testes postergados, os quais abrangeram seis modalidades de testes, a saber: julgamento de gramaticalidade cronometrado, julgamento de gramaticalidade não cronometrado, imitação oral, descrição livre de sequência de imagens, descrição controlada de sequência de imagens e narrativa oral. Para fins de análise estatística dos dados, utilizamos o software International Business Machine Statistical Package for Social Studies (SPSS), a partir do qual fizemos uso de frequência relativa, teste de qui-quadrado e teste de Anova de medidas repetidas. A seguir, apresentamos a análise e discussão dos resultados.

\section{Análise e discussão dos resultados}

A seguir, indicamos a frequência global das formas clíticas de terceira pessoa e, posteriormente, tratamos do efeito e da durabilidade da intervenção instrucional em relação à produtividade, por separado, dessas formas como estruturas simples e complexas. Quanto à apresentação dos resultados estatísticos, inicialmente, indicamos a frequência relativa e, em seguida, apresentamos a estatística inferencial (teste de $\chi^{2}$ e Anova 
de medidas repetidas) a fim de apontarmos o que se mostrou relevante estatisticamente e de explicarmos o comportamento das formas sob análise.

\section{Frequência global}

Do cômputo total (4438 dados), 2747 ocorrências $^{8}$ remetem às formas simples, enquanto o restante dos dados alude aos contextos de ocorrência das formas complexas. Desses totais, 56\% (1543/2747) representam a produtividade das formas simples, ao passo que 54\% (911/1691) aludem à frequência das formas complexas. A fim de ilustrarmos os índices gerais, referentes à produtividade das formas clíticas de terceira pessoa, apresentamos, a seguir, o Gráfico 1.

GRÁFICO 1 - Produtividade global das formas simples e complexas

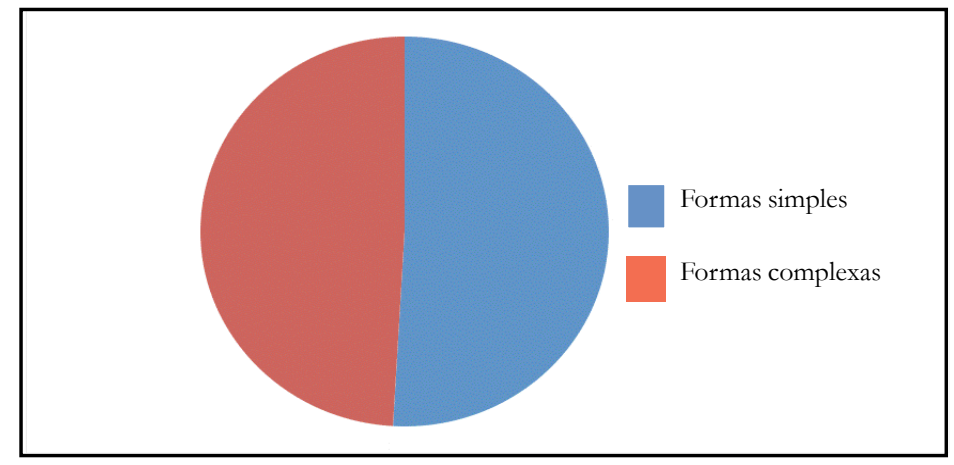

Fonte: Elaborado pelo autor.

A partir dos dados anteriores, podemos observar que as formas simples, com frequência de 56\%, obtiveram o maior índice de produtividade, em comparação ao percentual das formas complexas. Entretanto, esses resultados não nos permitem afirmar que as formas simples foram as que obtiveram maior produtividade, visto que os percentuais de ambas as formas clíticas de terceira pessoa foram próximos.

Ainda que haja indícios de que as formas simples e complexas se comportaram de maneira similar, em termos de frequência, não podemos corroborar essa tendência e tampouco refutá-la, uma vez que os índices são gerais. Em outras palavras, esses valores são produto da soma dos índices de

\footnotetext{
${ }^{8}$ Contextos criados para a identificação e/ou aplicação das formas simples e complexas.
} 
produtividade das formas linguísticas sob análise, durante todas as etapas de coleta de dados, o que não nos permite verificar se houve, ao longo das fases I e II pós-tratamento instrucional, que correspondem, respectivamente, às coletas dos dados provenientes do pós-teste imediato e do pós-teste postergado, aumento, avanço, queda ou manutenção dos seus percentuais. Em virtude disso, para conduzirmos uma discussão mais detalhada sobre a frequência das formas clíticas de terceira pessoa do espanhol, seguiremos com a apresentação dos resultados estatísticos.

Nossa hipótese de que a intervenção pedagógica traria efeito durável sobre a produtividade das formas simples e complexas, em curto e em médio prazos, foi confirmada.

A fim de evidenciarmos que as produções linguísticas dos indivíduos deste estudo, em fase anterior ao tratamento pedagógico, apresentavam inadequações, no que tange ao uso das formas-alvo, apresentamos os exemplos ${ }^{9}$ a seguir.

(1) El gato miró el pescado sobre la mesa subiu para agarrar Ø (lo) no consiguiu llevar él (lo) Ø (lo) comió allí mismo Ø (lo) encontró riquísimo.

(Informante 3, fase pré-instrucional, teste de produção oral)

(2) El gato olió a la carne después (1a) vin la carne sobre la mesa después subiu para agarrar Ø (la) pero no Ø (Ia) conseguiu llevar Ø (Ia) comió alli mismo Ø (la) encontróse riquísima.

(Informante 6, fase pré-instrucional, teste de produção oral)

(3) La madre de Juanita le dio un regalo, una joya preciosa y Juanita le Ø (se 1a) mostró para sus amigas que 1e Ø (se 1a) pidieron emprestada, pero Juanita no Ø Ø (se la) puede emprestar.

(Informante 8, fase pré-instrucional, teste de produção oral)

(4) La bistoria es sobre una señora que dio a su hija una joya muy bonita. Notro día su bija Ø Ø (se 1a) llevópra escuela y Ø Ø (se la) mostró a sus colegas. Sus colegas gustaron mucho $\boldsymbol{\varnothing}$ Ø (se 1a) pediron emprestada.

(Informante 1, fase pré-instrucional, teste de produção oral)

Conforme podemos observar, no excerto (1), o informante 3, em vez de aplicar a forma $\mathbf{l o}$, clítico acusativo de terceira pessoa, não a realizou foneticamente, isto é, fez uso da forma nula. De modo similar, o informante

\footnotetext{
${ }^{9}$ As formas que estão entre parênteses correspondem à forma-alvo não produzida pelos informantes.
} 
6, além de não realizar foneticamente o clítico acusativo la, utilizou, no seu lugar, a forma la carne, sintagma nominal repetido. Por último, nos exemplos restantes, os informantes empregaram as formas nulas, em vez dos clíticos, em função acusativa e dativa, ou usaram a forma clítica de terceira pessoa, em função dativa, acompanhada de forma nula.

Essa tendência de emprego de outras formas linguísticas, em vez das formas clíticas de terceira pessoa, está de acordo com a literatura da ASL (CRUZ, 2001; GONZÁLEZ, 1994; LOZADA, 2007; SEBOLD, 2002, 2006; SIMÕES, 2009; VANPATTEN, 1990; VILLALBA, 1995; YOKOTA, 2007), segundo a qual as formas clíticas de terceira pessoa são problemáticas aos aprendizes de espanhol, o que corrobora a relevância da intervenção pedagógica adotada neste estudo.

A fim de discutirmos o efeito e a durabilidade do tratamento pedagógico, destinado ao ensino das formas simples e complexas, apresentamos o Quadro $1,{ }^{10}$ a seguir.

QUADRO 1 - A produtividade das formas simples e complexas nas etapas de coleta de dados

\begin{tabular}{|l|c|c|}
\hline \multicolumn{1}{|c|}{ Fator } & Formas simples & Formas complexas \\
\hline Pré-testes (PR) & $329 / 1352=24,3 \%$ & $110 / 1352=8,1 \%$ \\
\hline Pós-testes imediatos (PI) & $522 / 1493=35 \%$ & $397 / 1493=26,6 \%$ \\
\hline Pós-testes postergados (PP) & $692 / 1593=43,4 \%$ & $404 / 1593=25,4 \%$ \\
\hline
\end{tabular}

Fonte: Elaborado pelo autor.

No Quadro 1, a partir da comparação entre o PR, etapa anterior à intervenção instrucional, o PI, fase I pós-tratamento instrucional, e o PP, fase II pós-intervenção pedagógica, em relação à produtividade das formas simples, por um lado, podemos observar que o aumento de frequência dessas formas clíticas de terceira pessoa que iniciou, em curto prazo, no PI, prosseguiu, em médio prazo, no PP. Por outro lado, também constatamos, no Quadro 1, que as formas complexas foram produtivas, em curto

\footnotetext{
${ }^{10}$ No Quadro 1, os dados totais são distintos, por tipo de teste, em função do número de dados que foram gerados em cada etapa de coleta. Logo, a indicação individual da frequência das formas-alvo está baseada na porcentagem total (de 100\%) de cada tipo de teste.
} 
prazo, enquanto, em médio prazo, com uma sutil redução do seu índice de frequência, essas formas linguísticas se mantiveram praticamente estáveis.

A fim de realizarmos uma análise estatisticamente mais precisa, que possibilite verificarmos se existe ou não associação entre a intervenção instrucional e a frequência das formas simples e complexas, e se há diferenças significativas de sua produtividade, nas distintas etapas de coleta de dados, utilizamos, respectivamente, o teste de $\chi^{2}$ e o teste de Anova de medidas repetidas.

O valor do teste de $\chi^{2}$ (de $\chi^{2}=458,307$; valor $\mathrm{p}=0,00$ ) e os índices do teste de Anova de medidas repetidas, com os valores $\mathrm{p}=0,011 \mathrm{e} \mathrm{p}=0,021$, foram significativos estatisticamente. $\mathrm{O}$ resultado do primeiro teste estatístico sugere que o comportamento das formas-alvo, nas etapas pós-intervenção pedagógica, no que concerne ao aumento de sua frequência, não foi aleatório. Dito de outra maneira, em curto e em médio prazos, existe associação entre o tratamento instrucional e a frequência das formas simples e complexas.

Essa tendência é sustentada pelo resultado do teste Anova de medidas repetidas, o qual rejeita a hipótese nula. Isso significa que existe interação entre o aumento de produtividade das formas simples e complexas, conforme observamos no Quadro 1, nas fases I e II pós-tratamento instrucional, e a intervenção pedagógica. Para fins de visualização da produtividade das formas clíticas de terceira pessoa do espanhol, em curto e em médio prazos, apresentamos, a seguir, o Gráfico $2 .{ }^{11}$

GRÁFICO 2 - A diferença de produtividade das formas simples e complexas ao longo das etapas de coleta de dados

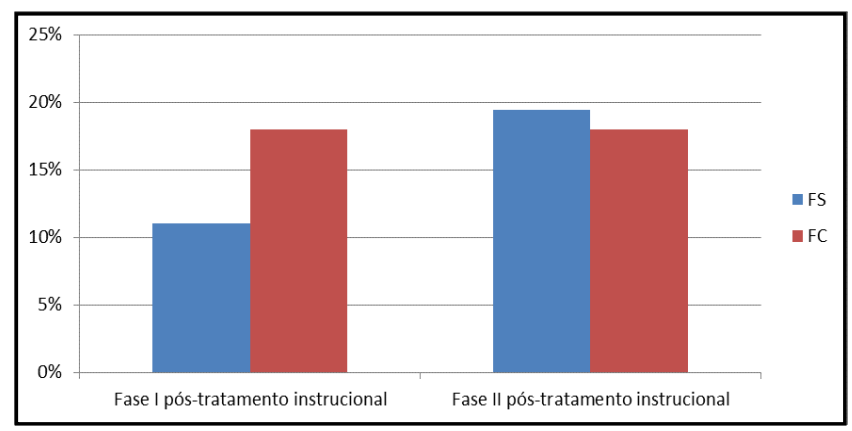

Fonte: Elaborado pelo autor.

${ }^{11}$ No Gráfico 2, FS=formas simples e $\mathrm{FC}=$ formas complexas. 
Conforme podemos observar, no Gráfico 2, nas fases I e II pósintervenção instrucional, ambas as formas clíticas de terceira pessoa se beneficiaram do tratamento instrucional. Esses resultados sugerem que essas formas linguísticas se mostraram sensíveis à intervenção pedagógica, com margem a favor das formas simples e complexas, respectivamente, em médio e em curto prazos.

Partindo do pressuposto de Schmidt (2001), de que a ASLé ocasionada primordialmente por aquilo que os aprendizes prestam atenção e percebem no insumo da língua-alvo e por aquilo que entendem como significado do insumo percebido, o tratamento instrucional deste estudo incluiu uma série de estratégias pedagógicas que podem ter possibilitado que os aprendizes testassem hipóteses sobre as formas clíticas de terceira pessoa e/ou percebessem problemas em relação ao seu uso (SWAIN, 1995, 2005).

Quando os aprendizes têm de executar tarefas de produção linguística na língua-alvo, podem encontrar dificuldades em realizá-las, pois, muitas vezes, o seu conhecimento linguístico não permite que comuniquem a mensagem pretendida com acurácia, conforme sugerem os exemplos de (1) a (4). Com base nessas evidências, conjecturamos que as alunas participantes possam ter encontrado dificuldades para executá-las e percebido que não sabiam produzir as formas-alvo com acuidade.

$\mathrm{Na}$ fase de produção linguística, quando foi necessário, houve correção explícita, e, posteriormente, os professores colaboradores forneceram instrução explícita às alunas participantes, de modo que hipóteses acerca do seu uso, que não condiziam com as regras do espanhol, foram refutadas. Por conseguinte, é provável que o feedback corretivo (LYSTER; RANTA, 1997; SPADA, 1997) tenha ocasionado a percepção das formas linguísticas sob análise e de problemas relacionados à sua aplicação, possibilitando, deste modo, reflexão sobre suas hipóteses a respeito das formas clíticas de terceira pessoa do espanhol e, consequentemente, a reformulação de seus enunciados.

Além disso, as informações sobre o funcionamento das formas-alvo propiciaram condições para que os aprendizes percebessem a diferença entre a sua representação mental e o seu real funcionamento no insumo instrucional. Em outras palavras, é possível que as evidências positivas ${ }^{12}$ sobre as formas-alvo tenham levado as alunas participantes a perceberem

${ }^{12}$ Exemplos de sentenças bem formadas na língua-alvo. 
que a ausência de realização fonética, como nos exemplos anteriores de (1) a (4), não estava em consonância com as regras da língua-alvo que requerem o uso separado dos clíticos acusativos ou em situação de coocorrência com os clíticos dativos.

A fim de ilustrarmos a produtividade das formas simples e complexas, em curto e em médio prazos, apresentamos os seguintes exemplos:

(5) Pedro vio la computadora la usó, dejó sobre el sofá. Pedro la mostró a su hermano. Su hermano la usó.

(Informante 3, fase I pós-tratamento, teste de produção oral)

(6) Rogerio viu unos guantes, los usó, después los compró, en casa los usó nuevamente, los planchó, los guardó en la cocina.

(Informante 2, fase II pós-tratamento, teste de produção oral)

(7) Sofía fue almorzar/comer en un restaurante que se 10 recomendó una amiga.

(Informante 9, fase I pós-tratamento, teste de produção oral)

(8) Joaquín se fue de compras y vio una camisa en la vitrina, se acordó de mostrarle a su madre, entonces la agarró del ropero y se la mostró a su madre.

(Informante 9, fase II pós-tratamento, teste de produção oral)

Nos exemplos de (5) a (8), a frequência das formas-alvo, balizada por testes estatísticos, sugeriu que o tratamento instrucional exerceu papel benéfico na aprendizagem das formas-alvo. Assim sendo, a intervenção pedagógica como um todo, com predomínio da instrução explícita, produziu efeitos positivos e duráveis sobre o aumento da frequência das formas clíticas de terceira pessoa do espanhol.

Estudos de síntese narrativa (SPADA, 1997) e de metanálise (NORRIS; ORTEGA, 2000; SPADA; TOMITA, 2010) têm apontado resultados favoráveis da instrução explícita na ASL. No contexto brasileiro, houve pesquisas sobre a IFF que corroboraram os benefícios desse tipo de intervenção pedagógica em relação à aquisição de formas linguísticas. Nesse sentido, por um lado, determinadas investigações (MÜLLING, 2007; NASCIMENTO, 2009; ZILLES, 2001), na ASL, indicaram que a instrução explícita produziu efeitos benéficos. Por outro lado, outros estudos (ALVES, 2004; LIMA JÚNIOR, 2008; LOOSE, 2006; MORAES, 2014; PASQUALI, 2012) sugeriram a durabilidade dos benefícios instrucionais, de natureza explícita, no processo de aprendizagem de LE/L2. 
Nesta investigação, quanto ao efeito instrucional e à sua durabilidade, os resultados sobre a produtividade das formas complexas estão em consonância com os trabalhos (LIMA JÚNIOR, 2008; MORAES, 2014; MORAES; DUTRA; SIMIONI, 2018; PASQUALI, 2012) nos quais o efeito instrucional foi durável. Em comparação, a produtividade das formas simples está de acordo com estudo de Loose (2006) cujos resultados apontaram que o aumento dos índices de produtividade de estruturas morfológicas do espanhol, em curto prazo, continuou na etapa seguinte de coleta de dado. Logo, as formas simples e complexas se beneficiaram em curto e em médio prazos, diferentemente da intervenção pedagógica.

\section{Considerações finais}

Esta investigação nos possibilitou examinar, em curto e em médio prazos, a interação entre o tratamento instrucional e o grau de complexidade dos clíticos de terceira pessoa do espanhol, caracterizados como estruturas simples e complexas. Para nortearmos esta pesquisa, partimos dos objetivos e das hipóteses apontados anteriormente, os quais retomamos, na sequência, a fim de tecermos as considerações finais do presente estudo.

O primeiro objetivo desta pesquisa estava relacionado ao efeito instrucional sobre a frequência das formas simples e complexas em curto prazo. Em relação a essa questão, nossa hipótese, a respeito do efeito da IFF sobre a produtividade das formas-alvo, foi confirmada. De modo geral, os resultados sugeriram que o conjunto de estratégias pedagógicas administradas às alunas participantes parece ter promovido o intake, visto que houve um aumento de frequência das formas simples e complexas em curto prazo, comportamento que foi balizado por testes estatísticos, a saber: teste de $\chi^{2}$ e o teste de Anova de medidas repetidas. Contudo, é válido destacarmos que, em curto prazo, foram as formas complexas as que se mostraram mais sensíveis ao tratamento instrucional adotado.

O segundo objetivo desta investigação estava atrelado à durabilidade do efeito instrucional sobre a produtividade das formas simples e complexas. No que tange a esse aspecto, nossa hipótese também foi confirmada. As formas simples avançaram, isto é, em curto e em médio prazos, essas formas clíticas de terceira pessoa aumentaram continuamente os seus índices de frequência. Em contraste, as formas complexas obtiveram aumento de produtividade, em curto prazo, e se mantiveram praticamente estáveis, em 
termos de frequência, em médio prazo. De maneira geral, os resultados apontaram que as formas-alvo estão em processo de aprendizagem entre as alunas participantes.

A partir dos resultados obtidos, no que tange ao efeito instrucional e à sua durabilidade sobre a produtividade das formas sob análise, podemos afirmar que, apesar de o tempo de tratamento instrucional ter ocasionado efeitos benéficos sobre a aquisição das formas clíticas de terceira pessoa do espanhol, não resultou na sua aquisição propriamente dita. Por conseguinte, é necessário que não se compreenda a intervenção pedagógica administrada, em relação a formas linguísticas problemáticas, como ações pedagógicas definitivas.

A semelhança entre o PB e o espanhol não parece ser um aspecto que facilita o processo de aquisição dessa língua estrangeira. Estamos de acordo com Villalba (2002), para quem a dificuldade do brasileiro no processo de aprendizagem do espanhol tem relação com a semelhança/falsa semelhança em termos de indefinição de limites linguísticos entre essa língua e o PB. Nesse sentido, provavelmente a estratégia pedagógica, referente ao contraste entre ambas as línguas, a respeito do funcionamento das formas clíticas de terceira pessoa, atrelada a outras estratégias pedagógicas, tenha promovido a percepção dos limites de proximidade e de distância na área do sistema pronominal do espanhol em relação ao PB. Portanto, no caso de línguas próximas (língua materna e LE), do ponto de vista didático-metodológico, parece ser eficiente e necessária a indicação aos aprendizes do limite de proximidade interlinguística, enfatizando os aspectos divergentes.

A contribuição do presente trabalho, para a área de ASL, está relacionado ao caráter intervencionista, no que concerne ao estudo de aquisição das formas clíticas de terceira pessoa do espanhol, visto que, no contexto brasileiro, as pesquisas sobre a aprendizagem dessas formas linguísticas do espanhol tendem a ser de natureza descritiva ou relacional, conforme já apontamos na introdução. Além disso, esta investigação trata da interação entre tratamento instrucional e o grau de complexidade das formas linguísticas, tema que é ainda pouco explorado no país.

Por último, quanto às limitações do presente estudo, assinalamos o número reduzido de alunas participantes. $O$ fato de termos perdido informantes, ao longo da aplicação da pesquisa, nos permite conjecturar que o número de testes aplicados, durante as etapas de coleta de dados, 
parece ter influenciado a desistência dos alunos participantes habilitados (18 estudantes) a fazer parte de todas as fases de obtenção dos dados. Contudo, o número reduzido de informantes parece não ter afetado a indicação de evidências favoráveis do tratamento instrucional na aprendizagem das formas simples e complexas, visto que os testes (qui-quadrado e Anova de medidas repetidas) apresentaram índices que se mostraram relevantes estatisticamente.

\section{Referências}

ALVES, U. K. O papel da instrução explícita na aquisição fonológica do inglês como L2: evidências fornecidas pela teoria da otimidade. 2004. 335f. Dissertação (Mestrado em Letras) - Universidade Católica de Pelotas, Pelotas, 2004.

CARVALHO, V. O. Os efeitos da instrução na aquisição-aprendizagem lexical: explícito vs implícito. 2017. 254f. Dissertação (Mestrado em Língua, Literatura e Cultura Italianas) - Faculdade de Filosofia, Letras e Ciências Humanas, Universidade de São Paulo, São Paulo, 2017.

CRUZ, M. L. O. B. Estágios de interlingua: estudo longitudinal centrado na oralidade de sujeitos brasileiros aprendizes de Espanhol. 2001. 316f. Tese (Doutorado em Linguística Aplicada) - Institutos de Estudos da Linguagem, Universidade Estadual de Campinas, Campinas, 2001.

DUTRA, E. de O. A interação entre o tratamento instrucional e a prontidão de desenvolvimento de aprendizes no processo de aquisição dos clíticos de terceira pessoa do espanhol. Dominios de Lingu@gem, Uberlândia, v. 13, p. 212-232, 2019. Doi: https://doi.org/10.14393/DL37-v13n1a2019-9

DUTRA, E. O.; SIMIONI, T.; LIMA, M. S. A realização dos objetos direto e indireto anafóricos em português brasileiro e espanhol. Lingua e Instrumentos Linguísticos, Campinas, v. 1, n. 38, p. 55-78, 2016.

ELLIS, R. Investigating form-focused instruction. Language Learning, [S. l.], v. 51, p. 1-46, 2001. Doi: https://doi.org/10.1111/j.1467-1770.2001.tb00013.x

FREITAS, P. G. Os efeitos de duas estratégias de ensino, uma implícita e outra explícita, na aprendizagem do presente e do passato prossimo do italiano como lingua estrangeira. 2014. 200f. Tese (Doutorado em Linguística) - Universidade Federal de Santa Catarina, Florianópolis, 2014.

GONTIJO, E. A. O foco na forma de verbos frasais para aprendizes iniciantes de inglês como lingua estrangeira: uma nova proposta. 2001.161f. Dissertação (Mestrado em Estudos Linguísticos) - Universidade Federal de Minas Gerais, Belo Horizonte, 2001. 
GONZÁLEZ, N. T. M. Cadê opronome? O gato comeu. 1994. 451f. Tese (Doutorado em Letras) - Faculdade de Filosofia, Letras e Ciências Humanas, Universidade de São Paulo, São Paulo, 1994.

LIMA JÚNIOR, R. M. Pronunciar para comunicar: uma investigação do efeito do ensino explícito da pronúncia na sala de aula de LE. 2008. 243f. Dissertação (Mestrado em Linguística Aplicada) - Universidade de Brasília, Brasília, 2008.

LONG, M. Focus on form: a design feature in language teaching methodology. In: DE BOT, K.; GINSBER, R. B.; KRAMSCH, C. (Ed.). Foreign - language research in cross-cultural perspective. Amsterdam: Benjamins, 1991. p. 39-52. Doi: https:// doi.org/10.1075/sibil.2.07lon

LONG, M. H.; ROBINSON, P. Focus on form: theory, research, and practice. In: DOUGHTHY, C.; WILLIAMS, J. (Ed.). Focus on form in classroom second language acquisition. Cambridge: CUP, 1998. p. 15-42.

LONG, M.; ROBINSON, P. Focus on form: theory, research, and practice. In: DOUGTHY, C.; WILLIAMS. J. (Ed.). Focus on form in classroom second language acquisition. Cambridge; CUP, 1998. p.01-11.

LOOSE, R. E. O papel da instrução explícita na aquisição/aprendizagem de estruturas do espanbol por falantes do português. 2006. 187f. Dissertação (Mestrado em Letras) Universidade Católica de Pelotas, Pelotas, 2006.

LOZADA, P, R. A aquisição dos pronomes pessoais da lingua espanhola por falantes de português do Brasil: aspectos linguísticos e psicotipológicos. 2007. 182f. Dissertação (Mestrado em Linguística Aplicada) - Universidade de Brasília, Brasília, 2007.

LYSTER, R.; RANTA, L. Corrective feedback and learner uptake negotiation of form in communicative classroom. Studies in Second Language Acquisition, [S. l.] v. 9, p. 37-66, 1997. Doi: https://doi.org/10.1017/S0272263197001034

MORAES, G. B. A aprendizagem do presente do subjuntivo do espanbol por alunos brasileiros: um estudo com foco na forma. 2014. 168f. Tese (Doutorado em Linguística Aplicada) - Universidade do Vale do Rio dos Sinos, São Leopoldo, 2014.

MORAES, G. B.; DUTRA, E. O.; SIMIONI, T. A aprendizagem do presente do subjuntivo do espanhol em orações temporais com cuando por universitários brasileiros: os efeitos da intervenção instrucional na redução de transferência linguística. Trabalhos em Linguística Aplicada, Campinas, v. 57, n. 1, p. 467-491, 2018. Doi: https://doi.org/10.1590/010318138650065300251

MÜLLING, L. T. Notar e aprender: o papel da instrução explícita na aquisição da pragmática da L2. 2007. 201f. Dissertação (Mestrado em Letras) - Universidade Católica de Pelotas, Pelotas, 2007. 
NASCIMENTO, D. M. do. O papel da instrução explícita e implícita no ensino/ aprendizagem de locuçoes verbais em inglês. 2009. 110f. Dissertação (Mestrado em Letras) - Universidade Federal do Rio Grande do Sul, Porto Alegre, 2009.

NORRIS, J.; ORTEGA, L. Efectiveness of L2 instruction: a research synthesis and quantitative meta-analysis. Language Learning, [S. l.], v. 50, p. 417-528, 2000. Doi: https://doi.org/10.1111/0023-8333.00136

PASQUALI, E. O papel da instrução explícita e da memória de trabalho na leitura em L2. 2012. 121 f. Dissertação (Mestrado em Letras) - Universidade Católica de Pelotas, Pelotas, 2012.

PEROZZO, R. V. Percepção de oclusivas não vozeadas sem soltura audivel em codas finais do inglês (L2) por brasileiros: o papel da instrução explícita e do contexto fonéticofonológico. 2013. 193f. Dissertação (Mestrado em Letras) - Universidade Federal do Rio Grande do Sul, Porto Alegre, 2013.

PREUSS, E. O. A interface entre os conbecimentos implícito e explícito: um estudo baseado no aspecto verbal. 2005. 165f. Dissertação (Mestrado em Letras) - Universidade Católica de Pelotas, Pelotas, 2005.

SCHMIDT, R. Attention. In: ROBINSON, P. (Ed.) Cognition and second language instruction. Cambridge: Cambridge University Press, 2001. p. 3-32. Doi: https:// doi.org/10.1017/CBO9781139524780.003

SEBOLD, M. M. R. Falantes de PB aprendendo EL2 e os clíticos. In: CONGRESSO BRASILEIRO DE HISPANISTAS, 4., 2006, São Paulo. Anais [...]. São Paulo: USP, 2006. p. 222-226.

SEBOLD, M. M. R. Q. Distribuição de clíticos no Espanhol e no PB e a repercussão no ensino de Espanhol L2. In: CONGRESSO BRASILEIRO DE HISPANISTAS, 2., 2002, São Paulo. Anais eletrônicos [...]. São Paulo: USP, 2002. Disponível em: https://bit.ly/2VTvDRz. Acesso em: 31 de maio de 2014.

SHINTANI, N.; LI, S.; ELLIS, R. Comprehension-based versus production-based grammar instruction: a meta-analysis of comparative studies. Language Learning, [S. l.], v. 63, n. 2, p. 296-329, 2013. Doi: https://doi.org/10.1111/lang.12001

SIMÕES, A. Clítico, objeto nulo ou pronome tônico? Quanto e como a variação/mudança no paradigma do preenchimento pronominal do objeto acusativo de terceira pessoa no português brasileiro se reflete na aquisição/aprendizagem do espanhol pelos aprendizes brasileiros ao longo das gerações. 2010. 248f. Dissertação (Mestrado em Língua Espanhola e Literaturas Espanhola e Hispano-Americana) - Faculdade de Filosofia, Letras e Ciências Humanas, Universidade de São Paulo, São Paulo, 2010. 
SIMÕES, A. M. Algumas tendências da realização do objeto direto pronominal de terceira pessoa no processo de aquisição/aprendizagem formal de Espanhol por falantes do português brasileiro. Papia, Brasília, DF, v. 19, p. 233-246, 2009.

SPADA, N. Form-focused instruction and second language acquisition: a review of classroom and laboraty research. Language Teaching, [S. l.], v. 30, p. 73-87, 1997. Doi: https://doi.org/10.1017/S0261444800012799

SPADA, N.; LIGHTBOWN P. M. Form-focused instruction: isolated or integrated? TESOL Quartely, [S. l.], v. 42, n. 2, p. 181-207, 2008. Doi: https://doi. org/10.1002/j.1545-7249.2008.tb00115.x

SPADA, N.; TOMITA, Y. Interactions between type of instruction and type of language feature: a meta-analysis. Language Learning, [S. l.], v. 60, n. 2, p. 1-46, 2010. Doi: https://doi.org/10.1111/j.1467-9922.2010.00562.x

SWAIN, M. Atención a la forma através de la reflexión consciente. In: DOUGHTY, C.; WILLIAMS, J. (Org.). Atención a la forma en la adquisición de segundas lenguas en el aula. Madrid: Edinumen, 1998.

SWAIN, M. The output hypothesis: theory and research. In: HINKEL, E. (Org.). Handbook on research in second language teaching and learning. New Jersey: Lawrence Erlbaum Associates, 2005. p. 471-483.

SWAIN, M. Three functions of output in second language learning. In: COOK, G.; SEIDLHOFER, B. (Org.). Principles and practice in applied linguistics: studies in honour of H. G. Widdowson. Oxford: Oxford University Press, 1995. p. 125-144.

TODE, T. Durability problems with explicit instruction in an EFL context: the learning of the English copula be before and after the introduction of the auxiliary. Language Teaching Research, [S. l.], v. 11, n. 1, p. 11-30, 2007. Doi: https:// doi.org/10.1177/1362168806072398

VANPATTEN, B. The acquisition of clitic pronouns in Spanish: two case studies. In: VANPATTEN, B.; LEE, J. Second language acquisition-foreign language learning. Clevedon: Multilingual Matters, 1990. p. 118-39.

VILLALBA, T. K. B. A transferência na aquisiz̧ão da anáfora pronominal em espanbol por universitários brasileiros. 1995. 90f. Dissertação (Mestrado em Letras) - Universidade Federal do Rio Grande do Sul, Porto Alegre, 1995.

WILLIAMS, J.; EVANS, J. ¿Qué clase de atención y a qué formas? Atención a la forma en la adquisición de segundas lenguas en el aula. Madrid: Edinumen, 1998. 
YOKOTA, R. O que en falo não se escreve. E o que eu escrevo alguém fala? A variabilidade no uso objeto direto anafórico na produção oral e escrita de aprendizes brasileiros de Espanhol. 2007. 219 f. Tese (Doutorado em Letras) - Faculdade de Filosofia, Letras e Ciências Humanas, Universidade de São Paulo, São Paulo, 2007. ZILLES, M. O ensino e a aquisição de vocabulário em contexto de instrução de língua estrangeira. 2001. 192f. Dissertação (Mestrado em Letras) - Universidade Federal do Rio Grande do Sul, Porto Alegre, 2001.

Data de submissão: 15/03/2018. Data de aprovação: 30/01/2019. 